\title{
DISCURSOS SOBRE RECREAÇÃO EM DISCIPLINAS DO CURSO DE EDUCAÇÃO FÍSICA DA UFMG (1969-1990)
}

Recebido em: 25/11/2017

Aceito em: 01/08/2018

\author{
Hilton Fabiano Boaventura Serejo ${ }^{1}$ \\ Universidade Federal dos Vales do Jequitinhonha e Mucuri (UFVJM) \\ Diamantina - MG - Brasil \\ Hélder Ferreira Isayama ${ }^{2}$ \\ Universidade Federal de Minas Gerais (UFMG) \\ Belo Horizonte $-\mathrm{MG}-$ Brasil
}

RESUMO: Este texto objetivou analisar os discursos veiculados sobre recreação pelas disciplinas do currículo formal do curso de Educação Física da Universidade Federal de Minas Gerais, no período de 1969 a 1990. Com relação às fontes, foram utilizados, principalmente, os documentos relacionados ao currículo prescrito. A tipologia documental se enquadra nas fontes escritas impressas e manuscritas. Com relação à análise dos dados, se deu através da análise de discurso inspirada na perspectiva arqueológica de Foucault. Os significados sobre a recreação estavam demarcados pelos enunciados interesse e prazer. A recreação se entrecruzaria com os discursos biológico, psicológico e sociológico numa tentativa de superar uma perspectiva biológica presente na formação à época. Além disso, a recreação foi enunciada como ocupação das horas de lazer e foi considerada uma atividade e/ou uma possibilidade de uso das horas de lazer.

PALAVRAS CHAVE: Recreação. Discursos. Currículo.

\section{DISCOURSES ON RECREATION IN DISCIPLINES OF THE UFMG PHYSICAL EDUCATION COURSE (1969-1990)}

ABSTRACT: This study aims to analyze the discourses of the recreation programs in the formal curricula of the Physical Education course of the Federal University of Minas Gerais, from 1969 to 1990 . Regarding the sources, the most relevant ones were the documents related to the prescribed curriculum. The documentary typology can be

\footnotetext{
${ }^{1}$ Doutor em Estudos do Lazer pela UFMG. Docente da Universidade Federal dos Vales do Jequitinhonha e Mucuri (UFVJM). Membro do Oricolé - Laboratório de Pesquisa sobre Formação e Atuação Profissional em Lazer da UFMG.

${ }^{2}$ Docente do Programa de Pós-Graduação em Estudos do Lazer da Universidade Federal de Minas Gerais (UFMG). Líder do Oricolé - Laboratório de Pesquisa sobre Formação e Atuação Profissional em Lazer da UFMG.
} 
found in handwritten and printed sources. The analysis of the data followed the principles of the Discourse Analysis inspired by the archaeological perspective of Michel Foucault. The meanings of recreation were defined by the statements of interest and pleasure. The recreation would intersect with the biological, psychological and sociological discourses in an attempt to overcome the biological perspective - extremely present at the time in the formation of the students. Recreation was enunciated as occupation of leisure hours and was considered an activity and/or a possibility of use of leisure time.

KEYWORDS: Recreation. Addresses. Curriculum.

\section{Introdução}

Integrada à Universidade Federal de Minas Gerais, oficializado através do Decreto-Lei n 997 de 21 de outubro de 1969 (BRASIL, 1969), a Escola de Educação Física de Minas Gerais ${ }^{3}$ (EEFMG) passou a ser denominada Escola de Educação Física da Universidade Federal de Minas Gerais (EEF-UFMG) e mantida pelo Governo Federal.

Assim sendo, no ano seguinte a federalização, o curso de Educação Física da UFMG sofreu uma mudança em sua matriz curricular, quando foram criadas as disciplinas Recreação I e Recreação II. Em 1977, essas disciplinas passaram a se chamar Teoria da Recreação e Prática da Recreação ${ }^{4}$. Nesse contexto, as questões que motivaram esse trabalho foram: quais discursos sobre a recreação foram veiculados em relação ao currículo do curso daquela época? e, quais foram as transformações presentes nas ementas, conteúdos, objetivos e nas referências dessas disciplinas?

Assim, o objetivo deste artigo foi analisar os discursos veiculados pelos estudos da recreação no currículo formal do curso de Educação Física da Escola de Educação

\footnotetext{
${ }^{3}$ A EEFMG tem suas raízes em 1952 pela união de duas outras Escolas de Educação Física. Uma era ligada ao Estado de Minas Gerais, fundada pelo governo de Juscelino Kubistchek (JK); a outra pertencia às Faculdades Católicas, Sociedade Mineira de Cultura, presidida por D. Cabral, Arcebispo da Capital, denominada Escola de Educação Física das Faculdades Católicas de Minas Gerais. Após a federalização da EEFMG, em 1969, ela foi integrada à UFMG e mudou a sua denominação para EEF-UFMG.

${ }^{4}$ Documentos da Seção de Ensino da UFMG, como os Planos de Ensino e as Atas da Congregação.
} 
Física, Fisioterapia e Terapia Ocupacional da Universidade Federal de Minas Gerais (EEFFTO-UFMG) $^{5}$, no período de 1969 a 1990. Para que essa proposição fosse atingida, perseguimos os seguintes objetivos específicos: descrever e discutir o que determinados discursos sobre recreação e lazer procuraram divulgar e legitimar nos currículos formais na EEFFTO-UFMG; identificar as estratégias discursivas presentes nos conteúdos, ementas e referências; compreender os significados difundidos sobre recreação no currículo prescrito da EEFFTO-UFMG.

A partir do objetivo descrito, esta pesquisa foi desenvolvida, tendo, por inspiração, a perspectiva arqueológica foucaultiana, na qual história, currículo e formação profissional convergem e consolidam-se na racionalidade de uma narrativa crítica e organizada do passado, (re)escrita no presente, mas com vistas para o futuro. Até mesmo porque a educação nunca é para ficar onde está, mas, uma proposta de transformação do futuro, pois, ninguém pensa a educação sem pensar em mudança (MAGALHÃES, 2013).

Neste ponto, ressaltamos que a compreensão dos discursos reveladores dos motivos da recreação se tornar um tema de estudos no curso de Educação Física em MG, demanda discutir as transformações pelas quais passaram os conteúdos das disciplinas que se dedicavam a essa especificidade do conhecimento. Portanto, a compreensão e discussão desses conteúdos terão significado quando analisados a luz da conjuntura dos fatos que os originaram.

\section{Método}

Para a realização da pesquisa utilizamos como fontes os documentos

\footnotetext{
${ }^{5}$ Em 1979 os cursos de Fisioterapia e Terapia Ocupacional passaram a ser ofertados nas dependências da EEF-UFMG, com isso iniciou-se o processo de mudança para a denominação Escola de Educação Física, Fisioterapia e Terapia Ocupacional (EEFFTO) da UFMG.
} 
relacionados ao currículo prescrito: o currículo formal que se materializou nos documentos da época, com todas as suas variáveis. Trata-se da abordagem do currículo como um plano, no nível do planejamento, como um documento que pretende legitimar um saber disciplinado. Esse currículo nos proporcionou um testemunho, uma fonte documental da estrutura institucionalizada de um determinado saber (GOODSON, 1991). Ao priorizar as análises desses documentos, entendemos que as prescrições são emanadas não somente dos órgãos políticos e administrativos, mas também dos textos, manuais, programas e programações do professor (VIÑAO. 2007). Portanto, compreendemos que os estudos dos discursos presentes nas disciplinas se iniciam com os documentos oficiais, assim as primeiras documentações pesquisadas foram os textos oficiais programáticos como ementas, programas, circulares, normas, leis etc.

Com relação à tipologia dos documentos consultados, eles se enquadram nas fontes escritas impressas e manuscritas, tais como: diários de classe, provas, atas da Congregação, atas do Conselho Técnico Administrativo, currículos dos professores responsáveis pela disciplina, leis e políticas educacionais da época. Esses documentos estavam arquivados nos diversos setores da EEFFTO-UFMG, como: a Seção de Ensino, o Colegiado de Graduação em Educação Física, o Departamento de Educação Física e o CEMEF.

Seguindo, pois, a inspiração foucaultiana, contextualizamos os documentos coletados, pois, como ocorre com a formação profissional, nenhum documento é neutro, pois carrega consigo a visão de mundo dos responsáveis por sua elaboração. Contudo, as análises discursivas arqueológicas, baseadas em Foucault, revelam o que está explícito, o que está dito, logo, não analisam as intencionalidades que possam permear os documentos, mas os efeitos desses discursos na produção dos sujeitos. Nessa 
perspectiva, as histórias arqueológicas são móveis, pois se deslocam pelos discursos e pelas práticas, contornam os saberes e procuram descrever e individualizar os enunciados discursivos (FOUCAULT, 2008).

Para a análise dos discursos que se manifestaram nas disciplinas que estudaram a recreação, nos apoiamos na perspectiva foucaultiana, na qual os conceitos presentes em sua fase arqueológica ${ }^{6}$ foram essenciais, como: discurso, enunciado, enunciação, formação discursiva e saber. Além desses, as compreensões dos conceitos de poder e de regime de verdade compuseram o pano de fundo das discussões desenvolvidas para a compreensão das enunciações e das formações discursivas que permearam a emergência desses saberes estudados.

\section{Resultados e Discussões: Discursos disciplinares}

\section{As disciplinas Recreação I e Recreação II}

Com a federalização da EEFMG em 1969, os discursos sobre mudanças na matriz curricular do curso de Educação Física se intensificaram. Contudo, essas transformações se materializaram somente em 1973, com a implantação de uma nova matriz curricular na então EEF-UFMG ${ }^{7}$. Com isso, foram instituídas as disciplinas Recreação I e Recreação II.

As disciplinas Recreação I e Recreação II estavam sob a responsabilidade dos professores Odilon Ferraz Barbosa e Nella Testa Taranto ${ }^{8}$. Esta professora substituiu o

\footnotetext{
${ }^{6}$ Referimo-nos aos livros História da loucura, O nascimento da clínica, As palavras e as coisas e $A$ arqueologia do saber.

${ }^{7}$ Projeto de Modernização do Sistema Acadêmico, 1974.

${ }^{8}$ A primeira disciplina específica a abordar a recreação surgiu em 1963 na EEFMG. Nessa época, essa cadeira teve o docente Geraldo Pinto de Souza como o professor catedrático e o Odilon Ferraz Barbosa como o professor assistente. Todavia, com a morte do professor Geraldo Pinto de Souza, em março de 1970, o professor Odilon assume integralmente a cadeira de Recreação. A partir de 1971 a professora Nella Testa Taranto passa a atuar conjuntamente com o professor Odilon nessa disciplina (SILVA, 2005).
} 
professor Geraldo Pinto de Souza, devido ao seu falecimento em $1970^{9}$.

Assim, os professores Odilon e Nella passaram a ser os responsáveis pela elaboração dos discursos formais que emanavam dessas disciplinas ligadas à recreação. Dessa forma, é necessário entender que eles estavam autorizados a falar de determinados saberes, pois, baseado em Foucault (2008), quem fala só fala porque foi autorizado por algo ou por alguém e, por deter essa autoridade, esses docentes adotavam linguagens específicas aos temas de estudos.

Portanto, o papel social que o indivíduo assumia, nesse caso o de professor universitário, bem como o lugar institucional do qual esse discurso provinha, a EEFUFMG, importam na análise dos discursos inspirados na arqueologia foucaultiana, pois reforçam os efeitos de verdade produzidos nessas cadeiras (FOUCAULT, 2008).

Com referência à professora Nella Testa Taranto, nasceu em 1910 e atuou na EEFMG desde a década de 1960. Com a federalização dessa escola, passando a chamarse EEF-UFMG, e com o falecimento do professor Geraldo Pinto de Souza, ela assumiu a cadeira de Recreação conjuntamente com o professor Odilon Ferraz Barbosa (Barbosinha). A docente é autora de várias obras com o título Recreação em coautoria com Barbosinha e com Eva Moreira de Assis (ROSA; LINHALES, 2007).

Com relação a sua formação ${ }^{10}$ na área, frequentou o curso Superior de Educação Física na Escola Nacional de Educação Física da Universidade do Brasil, Rio de Janeiro (RJ); o curso Internacional de Ginástica Rítmica Moderna, no Instituto Superior de Educação Física de Roma; o curso de Ginástica Rítmica da Escola Jacques Dalcrose de Genebra, Suíça; o curso Ginástica Feminina Moderna, da Escola Nacional de Educação

\footnotetext{
${ }^{9}$ Diversos do professor Geraldo Pinto de Souza, 1958-1966.

${ }^{10}$ Currículo resumido da professora Nella.
} 
Física do Rio de Janeiro. Como professora ${ }^{11}$ no ensino superior de EF, atuou em diversas cadeiras, como: Metodologia da Educação Física, Pedagogia da Educação Física, Didática e Recreação na EEF-UFMG, entre outras ações.

Mas, será que a presença da professora Nella, nas disciplinas Recreação I e Recreação II, teria afetado os discursos sobre a recreação e o lazer na EEF-UFMG? Para responder a essa questão, buscamos compreender se houve ou não mudanças nas enunciações provenientes das fontes pesquisadas.

Para isso, um primeiro aspecto a explicar refere-se à recorrência nas fontes pesquisadas de conteúdos, objetivos e ementas explicitados da mesma forma nas duas disciplinas ligadas à recreação. Isso ficou claro no ementário do curso ${ }^{12}$, no qual os ofícios abordando a proposta de mudança curricular ${ }^{13}$ e os documentos que tratavam da distribuição de disciplinas ${ }^{14}$, apresentavam para ambas as cadeiras Recreação I e Recreação II os seguintes tópicos a serem trabalhados: “Origem - Objetivos - Lazer Valor cívico-social - Conceito - propriedades - orientação educacional - Danças, brinquedos, jograis, pequenos e grandes jogos - Ruas de Recreio”.

Com relação aos objetivos, as enunciações presentes no programa das disciplinas nos anos de 1973 e 1974 propunham a compreensão dos seguintes aspectos: "Importância da recreação na vida humana; Valor da recreação na escola, no lar e na rua (horas de lazer); Orientação didática para o uso adequado da Recreação; comemorar devidamente as datas cívicas e festivas; conhecer e valorizar o folclore nacional"15.

Os conteúdos abordados nessas disciplinas apresentavam uma diferenciação em relação aos aspectos da organização curricular e foram agrupados em seis unidades de

\footnotetext{
${ }^{11}$ Currículo resumido da professora Nella.

${ }^{12}$ Ementa Recreação, 1974.

${ }^{13}$ Ofícios Mudança Curricular, 1974.

${ }^{14}$ Distribuição das disciplinas, 1974.

${ }^{15}$ Programa Recreação, 1973 e 1974.
} 
ensino, denominadas: Conceito de recreação; propriedade da recreação; Recreação e educação (jogos); Recreação orientada; Rua de recreio; Folclore ${ }^{16}$.

Com relação a essas unidades de ensino, a primeira unidade, Conceito de recreação, abordava o histórico da recreação, interesse e prazer e a conceituação filosófica de prazer e dor. A segunda unidade, Propriedade da recreação, especificava que seria estudado, novamente, o binômio interesse e prazer e sua conceituação filosófica. A terceira unidade, Recreação e educação (jogos), citava a classificação dos jogos, a recreação espontânea e orientada, a iniciação desportiva e os pequenos e grandes jogos. A quarta unidade, Recreação orientada, tratava dos brinquedos cantados, dos jogos rítmicos, das danças e atividades rítmicas. A quinta unidade, Rua de Recreio, referia-se aos aspectos técnico-metodológicos para a organização dessa ação; Por fim, a sexta unidade, Folclore, tratava das características do fato folclórico e da carta folclórica $^{17}$.

Cabe, aqui, um parênteses para explicar que, nesse período, a disciplina Recreação era ofertada, também, no Programa de Expansão e Melhoria do Ensino Médio (PREMEN) ${ }^{18}$, pelos professores Odilon Ferraz Barbosa e Nella Testa Taranto. As enunciações presentes nos programas dessa disciplina ${ }^{19}$, nesse curso, demonstram que os conteúdos também estavam organizados em unidades de ensino, ou seja: unidade

\footnotetext{
${ }^{16}$ Plano de Curso, 1973 e 1974.

${ }^{17}$ Plano de Curso, 1973 e 1974.

${ }^{18}$ Foi durante o governo do presidente Artur da Costa e Silva que foi lançado o Programa de Expansão e Melhoria do Ensino Médio (PREMEN). Era uma parceria do governo federal com os Estados Unidos da América, através de um convênio com o Ministério da Educação e Cultura. Essa iniciativa visava modernizar o ensino médio para suprir a demanda por mão de obra especializa na época. O PREMEN era um curso de curta duração, um ano, para a formação de professores de EF para atuarem nos ginásios polivalentes que oferecessem formação profissional. Essa iniciativa ocorreu na EEF-UFMG nos anos de 1971 a 1973. Os interessados em frequentar o PREMEN podiam ser pessoas que não tiveram formação superior em EF, nesse caso eles estariam habilitados para atuar somente nas escolas polivalentes. Todavia, havia, também, aqueles que frequentavam o curso superior e desejavam atuar nessas escolas. Esses discentes pleiteavam uma vaga no referido curso, o que era denominado Curso de Reciclagem (OLIVEIRA, 2014).

${ }^{19}$ Programa Recreação, 1972.
} 
I - conceitos analíticos da recreação; unidade II - propriedades da recreação; unidade III - a recreação e a educação; unidade IV - a recreação orientada.

Dessa forma, ao comparar as fontes da disciplina Recreação, ofertada no PREMEN $^{20}$, com a ofertada no curso Superior de $\mathrm{EF}^{21}$ da EEF-UFMG, percebemos que os discursos emanados desses documentos eram semelhantes e, em muitos casos, idênticos.

Mas, retomando a questão dos conteúdos das unidades de ensino, a concepção de recreação associada às enunciações interesse e prazer $^{22}$ continuou a ser recorrente. Contudo, vários programas de ensino apontam que seriam trabalhados os Conceitos Analíticos da Recreação ${ }^{23}$, expressão grafada no plural. Isso reforça a premissa de que outras visões de recreação também seriam abordadas. A esse respeito, encontramos uma apostila arquivada junto com as fontes das disciplinas Recreação I e Recreação II. Esse material ajudou a compreender alguns dos múltiplos discursos que explicavam aspectos ligados a esse fenômeno. Referimo-nos à Apostila da Associação Brasileira de Recreação ${ }^{24}(\mathrm{ABDR})^{25}$, datada de 1973.

Constam, nessa apostila, diversos trabalhos de autores que pesquisavam as temáticas da recreação e alcançaram visibilidade nacional nessas áreas. Entre os diversos autores, destacamos os textos de Ethel Bauzer Medeiros ${ }^{26}$, Lenea Gaelzer ${ }^{27}$ e

\footnotetext{
${ }^{20}$ Diários de Classe e Programa de Ensino - Recreação - Escola de Educação Física da UFMG, 1973.

${ }^{21}$ Plano de Curso, 1973 e 1974.

${ }^{22}$ Planos de Curso, Provimento, Provas. 1971 a 1974.

${ }^{23}$ Programa Recreação, 1972.

${ }^{24}$ Apostilas Recreação, 1973.

${ }^{25}$ A Associação Brasileira de Recreação (ABDR) foi fundada em 1958 e teve como sua primeira presidente a professora Ethel Bauzer Medeiros (LIMA, 2009). Essa associação objetivava formar profissionais para atuar como recreadores e, entre suas ações, estava a realização do II Seminário de Recreação, realizado no Rio de Janeiro, em julho de 1971. Além disso, os associados à ABDR atribuíam uma visão salvadora à área, pois as contradições presentes na sociedade seriam compensadas pelos efeitos positivos que a recreação propiciaria (TEIXEIRA, 2008).

${ }^{26}$ Ethel Bauzer Medeiros graduou-se em pedagogia pela Universidade do Brasil e fez, também, o curso de Normalista Especializada em Educação Física nessa mesma instituição. Ela mostrou interesse pela área da recreação e, também, pela psicologia. Publicou diversos trabalhos sobre a recreação e o lazer, entre
} 
Ruth Gouvêa ${ }^{28}$.

O texto de Medeiros (1973) apresenta a recreação como uma área que trazia benefícios ao homem, por seu apoio à saúde mental e ao convívio social. Na visão dessa autora, quem trabalhasse com a recreação deveria favorecer as atividades criadoras, considerando alguns elementos presentes na recreação, como: a liberdade de escolha e a atitude de prazer no fazer. Pois, "na recreação o prazer está na própria atividade, que não visa ser útil nem trazer proveito ou lucro, porém apenas alegrar” (MEDEIROS, 1973, p.5). Nessa visão, a recreação teria a busca no prazer como o seu fim.

O trabalho de Gaelzer (1973), por sua vez, analisa a recreação como uma atividade humana que estaria presente em todas as sociedades, desde os tempos mais antigos, não havendo diferenciação rígida entre trabalho e recreação. Segundo ela, com a mecanização, as pessoas tiveram redução de seu horário de trabalho, ocasionando a seguinte questão: “Que deverão as pessoas fazer em suas horas livres?” (p.01). Em sua opinião, a sociedade caminharia para a civilização do lazer, cuja característica marcante desse fenômeno seria o tempo:

Lazer é o tempo livre sujeito as predisposições individuais. Lazer é constituído de uma atividade espontânea, desinteressada, isenta de preocupação, renovadora, que satisfazendo as necessidades fundamentais do ser humano, leva o mesmo a euforia e age como fator de ajustamento e felicidade (GAELZER, 1973, p.01).

Logo, a recreação seria "a atividade individual ou coletiva realizada

eles: Jogos para recreação na escola primária: subsídio à Prática da Recreação infantil, em 1959; Jogos para recreação infantil, em 1961; O lazer no planejamento urbano, em 1975; O município e a recreação, em 1976 (LIMA, 2009).

${ }^{27}$ Lenea Gaelzer, licenciada em educação física pela Escola Superior de Educação Física da Universidade Federal do Rio Grande do Sul (ESEF-UFRGS), participou de diversos cursos relacionados à recreação, atuou em políticas de lazer no Brasil, foi professora na ESEF-UFRGS e protagonista nas discussões sobre essa temática na ESEF-UFRGS. Além disso, publicou algumas obras sobre esses temas, entre elas: Lazer: benção ou maldição?, em 1979, Ensaio à liberdade: uma introdução ao estudo da educação para o tempo livre, em 1985 (FEIX, 2003).

${ }^{28}$ Ruth Gouvêa era membro diretor da Associação Brasileira de Recreação (GOUVÊA, 1973) e publicou várias obras relacionadas à temática, entre elas: Jogos Infantis (GOUVÊA, 1934), Os Jogos dirigidos na educação integral (GOUVÊA, 1949), Recreação (GOUVÈA, 1963). 
voluntariamente nas horas de lazer" (GAELZER, 1973, p.01). Assim, recreação continuava a ser abordada como atividade, e o lazer apresentava elementos ligados ao tempo livre e ao desinteresse pelas questões econômicas.

Por fim, no artigo de Gouvêa (1973), a recreação também era vista como atividade a ser desenvolvida nas horas de lazer e caracterizava-se "pela livre escolha, espontaneidade de ação, fim na própria atividade, prazer e ativa participação do ser humano" (p.01). Para essa autora, a atitude do participante definiria se uma atividade era ou não considerada recreativa. Isso ocorreria se essa ação fosse marcada pelo prazer, pela liberdade de execução e considerada como um fim em si mesma, sem outros interesses.

Essas autoras são/foram conhecidas no Brasil por possuírem várias publicações sobre recreação ou lazer e por terem atuado na formação profissional nessas áreas. Nos trabalhos delas, presentes na Apostila da Associação Brasileira de Recreação, encontram-se diferenciações entre recreação e lazer. A recreação relacionava-se com a atividade, não se restringindo apenas à idade infantil, era demarcada pela livre escolha e pela busca do prazer. Enquanto o lazer estaria demarcado pela questão do tempo livre das obrigações (MEDEIROS, 1973; GAELZER, 1973, GOUVÊA, 1973).

As enunciações dessas autoras aproximam as discussões da recreação aos usos adequados do lazer. Consideramos que esses discursos reforçavam a visão utilitária e moralista ligada a essas áreas, pois a definição do que era ou não adequado para ser vivenciado no tempo do lazer estava permeada pelos valores morais vigentes à época. Os usos do tempo livre pela sociedade deveriam ser controlados, com o intuito de formar pessoa úteis, produtivas e obedientes ao sistema em que estavam inseridas. Reforçando essa ideia, Gomes (2003) explica que com a institucionalização do lazer, foi 
necessário que os usos do tempo livre fossem controlados com fins utilitários. Assim, à época, prevaleciam os divertimentos considerados lícitos, saudáveis e produtivos, pelos segmentos hegemônicos da sociedade.

Retomando as discussões sobre as disciplinas Recreação $I$ e $I I$ da EEF-UFMG, comparamos as enunciações presentes nessas cadeiras com as que constavam na disciplina Recreação da EEFMG. Nessa análise, percebemos que as unidades de ensino de número um (01) a cinco (05) referiam-se a questões como o binômio interesse e prazer, a classificação dos jogos, a recreação orientada, os pequenos e grandes jogos, os brinquedos cantados, as atividades rítmicas e as Ruas de Recreio.

Assim, em suma, quando se puder descrever certo número de enunciados semelhantes, se apresentarem regularidades enunciativas, ordens, correlações ou funcionamentos similares, podemos dizer que temos uma formação discursiva. Em outras palavras, a formação discursiva se relaciona com as regularidades e semelhanças entre os enunciados num determinado momento e local (FOUCAULT, 2008).

Dessa forma, compreendemos que se estabeleceu uma formação discursiva entre essas cinco unidades, pois os discursos que se manifestaram nas disciplinas Recreação I e Recreação II da EEF-UFMG eram semelhantes aos presentes na extinta cadeira de Recreação da EEFMG. A junção desses saberes em unidades de ensino teve por objetivo organizar e agrupar os conteúdos em áreas que tivessem relações entre os conteúdos que seriam desenvolvidos nessas cadeiras.

Todavia, a sexta unidade, relacionada ao folclore, trazia enunciações sobre os conteúdos desenvolvidos que não faziam parte dos documentos anteriores, como: o conceito de folclore; a classificação dessa área; o fato folclórico; a carta folclórica ${ }^{29}$. Na

\footnotetext{
${ }^{29}$ Programa Recreação, 1973 e 1974.
} 
busca por compreender os discursos que permeariam a discussão desses saberes, encontramos uma apostila, organizada pela professora Nella Testa Taranto, fruto de pesquisas das obras de Edison Carneiro ${ }^{30}$, membro da Comissão Nacional de Folclore no período em questão.

Nessa apostila, denominada Pesquisa de Folclore, o vocábulo folclore estava associado a "uma série de maneiras de sentir, pensar e agir características das camadas populares nas sociedades civilizadas" ${ }^{\text {31 }}$. Entre as diversas manifestações populares, faziam parte do folclore os cantos populares, os provérbios, as advinhas, as rodas infantis e as danças, então denominados manifestações da vida do povo ${ }^{32}$.

Com relação à carta folclórica, a professora Nella referia-se à carta do Folclore Brasileiro que consubstanciou as deliberações do I Congresso Brasileiro de Folclore, ocorrido em agosto de 1951, conforme descrito a seguir:

Constituem o fato folclórico as maneiras de pensar, sentir e agir de um povo, preservado pela tradição popular e pela imitação e que não sejam diretamente influenciadas pelos círculos eruditos e instituições que se dedicam ou à renovação e conservação do patrimônio científico e artístico humano ou à fixação de uma orientação religiosa e filosófica (CARTA, 1951, p.1).

Nessa visão, o folclore abarcaria a vida popular e se estenderia a todas as ações, em todas as fases da vida, desde que estivessem presentes algumas características com relação ao fato folclórico, como: a aceitação coletiva, ser essencialmente popular, preservação da tradição e do anonimato (CARTA, 1951).

Com relação à classificação dos fatos folclóricos, segundo a apostila, eles eram

\footnotetext{
${ }^{30}$ Edison Carneiro nasceu em 1912 e faleceu em 1972. Foi etnólogo, folclorista, historiador e pesquisador da cultura popular, tendo participado de diversos movimentos e instituições que valorizavam o folclore brasileiro (CNFCP, 2017).

${ }^{31}$ Apostila Folclore - Programa Recreação, 1973.

${ }^{32}$ Apostila Folclore - Programa Recreação, 1973.
} 
dispostos da seguinte maneira ${ }^{33}$ :

a) Literatura oral (Folclore infantil): poesias, estórias, canções, advinhas, lendas, provérbios, mitos, parlendas, rondas, jogos, travalinguas.

b) Crendices e superstições: mula sem cabeça, lobisomem, cura do soluço, cura da gagueira, [...].

c) Lúdicas: danças e bailes, jogos, cortejos [...].

d) Artes e Técnicas: cerâmica, artesanato em geral [...]

e) Música: Musicas, o dom universal da música assume formas peculiares no seio do povo.

f) Usos e costumes populares relacionados com as atividades econômicas e sociais: a caça e a pesca, a habitação e a vestimenta [...]

g) Linguagem popular: metáforas, frases feitas [...]

Consequentemente, a temática do folclore passou a fazer parte das avaliações das disciplinas Recreação I e II, tanto em seus aspectos práticos, quanto teóricos. Com referência à avaliação prática, conforme o programa de ensino, a abordagem desse saber estava arrolada à "organização de números folclóricos e criativos", "participação nas apresentações em grupo", "participação, como assistentes, em programas relativos a área folclórica" ${ }^{34}$.

E, para a avaliação teórica a respeito do tema folclore, realizava-se uma prova objetiva. Como exemplo, citamos uma avaliação ocorrida em 1973, na qual quatorze (14) questões versavam sobre essa temática, dessas, doze (12) eram de múltipla escolha. Chamou-nos a atenção o fato de constar apenas o nome da professora Nella Testa Taranto como a responsável por essa avaliação. Uma vez que os documentos das disciplinas Recreação I e II apresentavam, majoritariamente, o nome dos dois professores.

Assim, as enunciações apresentam pistas que nos levam a inferir que os discursos sobre folclore foram demarcados pela professora Nella Testa Taranto. Essa ideia se avigora ao relembrar que essa temática estava presente nos programas de ensino

\footnotetext{
${ }^{33}$ Apostila Folclore - Programa Recreação, 1973.

${ }^{34}$ Programa Recreação, 1973 e 1974.
} 
na disciplina de Pedagogia da EEFMG, em 1965, ministrada pela referida docente, na qual abordava $A$ Educação pela recreação - folclore infantil ${ }^{35}$. Essas questões contribuem para reforçar a hipótese de que a mudança de protagonismo marcou as mudanças nos discursos sobre a recreação na EEF-UFMG

Outra questão inclusive que robustece essa conjectura refere-se à constatação de que alguns discursos deixaram de constar nos documentos analisados com as mudanças de professores responsáveis pela(s) disciplina(s) de Recreação. Referimo-nos, por exemplo, às enunciações arma de dois gumes, instrumento de dois gumes, que eram desenvolvidas pelo professor Geraldo Pinto de Souza na disciplina Metodologia do Treinamento Desportivo ${ }^{36}$, em 1955, e também abordadas na disciplina Recreação de 1963 a 1969, período de sua atuação nesse curso.

Além disso, percebemos que o protagonismo dos docentes Odilon Ferraz Barbosa e Nella Testa Taranto se manifestou em outras ações e espaços. Por exemplo, nos exames para o provimento da cadeira de Educação Física para as escolas estaduais de MG, a temática da recreação foi abordada nos concursos ocorridos na década de 1970. Assim, na lista de pontos para prova escrita dos concursos para provimento da cadeira de EF em estabelecimentos estaduais de ensino médio em MG, encontram-se vários itens sobre a recreação, a saber: a recreação em face das necessidades biopsicossociais do adolescente; a recreação como fator de desenvolvimento da personalidade; a recreação e as danças folclóricas; a recreação como aspiração acentuada da época atual; o recreio na escola; a recreação como atividade extraclasse ${ }^{37}$.

Entre esses temas, a recreação como aspiração acentuada da época atual foi uma

\footnotetext{
${ }^{35}$ Programa Pedagogia, 1965

${ }^{36}$ Pontos para a primeira prova parcial - Disciplina Metodologia do Treinamento Desportivo, Curso Superior de Educação Física - Escola de Educação Física de Minas Gerais, 1955.

${ }^{37}$ Provimento, 1969 e 1970.
} 
questão avaliada em algumas dessas provas de provimento, como as que ocorreram nas cidades de Tombos ${ }^{38}$ e em Monte Alegre de Minas ${ }^{39}$, ambas em MG.

Ao dissertarem sobre essa questão, os candidatos reiteravam os discursos que classificavam a recreação em ativa e passiva. Isso se evidencia na resposta de um dos pretendentes a essas vagas:

Ativa é aquela em que o indivíduo participa como parte integrante da atividade, como um jogo, uma dança, uma dramatização, isto é, qualquer atividade em que o corpo se movimenta. Passiva é aquela em que o indivíduo participa como simples expectador, colocando os músculos em descanso, como quando assiste um filme, uma peça teatral, uma competição esportiva, etc. (CANDIDATO EM TOMBOS, MG - CEMEF $)^{40}$.

Também presente nas respostas relativas a essa questão dizia respeito à associação da recreação com os termos interesse e prazer. Todavia, outro aspecto chamou a atenção: percebemos a correlação entre alguns elementos presentes nesses documentos, ou seja, foi recorrente encontrar os nomes dos professores Odilon Ferraz Barbosa e Nella Testa Taranto como membros da banca avaliadora desses concursos quando o tema a ser analisado nas provas era a recreação. Isso ocorreu em diversos locais, como nas provas realizadas nas cidades mineiras de Bom Jesus do Galho, Araxá, Tombos, Montalvânia e Ouro Fino ${ }^{41}$.

Em síntese, as fontes pesquisadas demonstraram o protagonismo dos professores Odilon e Nella, no período, em relação às discussões sobre a recreação. Tal fato, consequentemente, teria refletido no ambiente externo à EEF-UFMG. Essa repercussão poderia estar relacionada aos efeitos dos trabalhos desenvolvidos por esses docentes nas disciplinas Recreação I e Recreação II.

\footnotetext{
${ }^{38}$ Prova para Provimento da cadeira de Educação Física, 1971.

${ }^{39}$ Provimento - provas, 1971.

${ }^{40}$ Prova para Provimento da cadeira de Educação Física, 1971.

${ }^{41}$ Bancas Provimento, 1971.
} 
Assim, ao pensar nas conexões entre as disciplinas de Recreação I e II e as provas de provimento, consideramos necessário compreender como esse currículo impactou a formação em EF naquela época e quais os efeitos que produziu. Afinal, essas cadeiras assinalavam o que estudar e como relacionar isso na prática profissional do aluno. Em perspectiva foucaultiana, as disciplinas produzem o efeito de iluminar determinados objetos, saberes, articulá-los de acordo com alguns algoritmos, métodos de ensino, e, ainda, por constituírem regimes de verdade (VEIGA-NETO, 1996).

Todavia, essas cadeiras sofreram alterações, pois alguns discursos questionavam os caminhos da EEF-UFMG e desejavam mudanças de rumo para o curso de EF. Mas, para isso, seria necessário implantar um novo currículo, uma nova matriz curricular.

\section{Mudança Curricular - 1977}

Conforme apontado, a federalização provocou debates sobre a mudança na matriz curricular da EEF-UFMG e em março de 1973 foi implantado um novo currículo no curso de EF dessa instituição ${ }^{42}$. Com isso, foram criadas as disciplinas Recreação I e Recreação II.

Contudo, em 1974, a EEF-UFMG solicitou uma alteração na matriz curricular do curso e, para isso, encaminhou uma proposta ao Conselho de Graduação da UFMG. Tal alteração estava baseada no contexto de a EF ter tido ajuda econômica e apoio do poder público nas questões administrativas e pedagógicas, de forma não vivenciada anteriormente na instituição. Além disso, a política do Governo Federal, à época, aumentara as responsabilidades dos docentes de EF e dos técnicos desportivos. Com isso, argumentaram que todo esse investimento pouco valeria "se o pessoal técnico

\footnotetext{
42 Projeto de Modernização do Sistema Acadêmico, 1974.
} 
disponível não estiver capacitado para a execução cabal das tarefas de base" ${ }^{\text {,3 }}$.

Baseando-se nesses argumentos, propuseram a alteração da carga horária das disciplinas do curso de EF, entre elas a de Recreação, e a criação de algumas cadeiras. Mas, a maior modificação solicitada seria com referência à duração total do curso, que passaria de três para quatro anos. A alegação era que "todos os cursos de licenciatura da UFMG têm a duração de quatro anos. Não seria, pois, a Educação Física [...] que devesse ficar sujeita a uma carga formativa deficiente e a uma valorização secundária"44.

Com relação à base conceitual presente nessa proposta, encontramos um documento denominado Bases para reformulação de currículos e programas para o ensino fundamental: objetivos e desenvolvimento das matérias ${ }^{45}$, que apresentava indicações para auxiliar o planejamento de reformulação curricular na educação básica. Essa fonte estava arquivada conjuntamente com outras ligadas às discussões sobre mudança curricular que ocorreram em 1974. Diante desse material, ocorreu-nos a pergunta: as ideias emanadas desse texto teriam contribuído para as discussões sobre a reforma curricular pretendida naquele período?

As enunciações desse documento explicitavam que haveria um núcleo comum no currículo da educação fundamental e que essa formação não deveria se pautar apenas pela mera aquisição de conhecimentos, mas também pelo "preparo para a cidadania consciente e ativa" (p.2) ${ }^{46}$. Chamou a atenção o fato de constarem nesse documento críticas a uma perspectiva educacional tradicional e por ser essencial o "preparo para as horas de lazer. A recreação sadia, o esporte bem orientado" (ibidem).

\footnotetext{
${ }^{43}$ Proposta de alteração dos currículos e cargas horárias do curso de Educação Física, 1974.

${ }^{44}$ Proposta de alteração dos currículos e cargas horárias do curso de Educação Física, 1974.

${ }^{45}$ Bases para reformulação de Currículos, 1974.

${ }^{46}$ Bases para reformulação de Currículos, 1974.
} 
Dessa forma, deparamo-nos com um grupo de enunciações que revelaram influências das teorias curriculares críticas relacionadas à emancipação, à formação crítica e ao currículo oculto. Isso seria um avanço para um período regido por um sistema autocrático. Contudo: quem resolveria o que era considerado sadio? Pois, estava explicitada a preocupação com os usos e efeitos das horas de lazer na formação humana, devendo-se desenvolver uma conduta aceitável e aceitar as regras do jogo, sem questionamentos mais significativos.

Além desse documento, o Conselho de Graduação da UFMG produziu e publicou, em 1972, algumas diretrizes para a elaboração dos currículos de graduação dessa instituição. Desse modo, visavam-se homogeneizar critérios para criação de currículos e garantir flexibilidade curricular aos cursos. Essas diretrizes se manifestaram na Recomendação $n^{\circ}$ 02/72, que dispunha a respeito da elaboração de currículos. Ela veio para complementar a Recomendação $n^{\circ} 01 / 71$ que tratava da mesma questão ${ }^{47}$.

Conforme registra o trecho abaixo, as mudanças na estrutura educacional dos cursos deveriam abranger o currículo como uma sequência ordenada de disciplinas, hierarquizadas por meio de pré-requisitos. Além disso, seria composto por disciplinas que constassem no currículo mínimo de cada curso e de disciplinas complementares:

É de boa doutrina que se insista num aspecto: currículo constitui um todo orgânico. Presume uma organização de conhecimentos e técnicas, complementada por atividades essencialmente formativas. $\mathrm{O}$ currículo mínimo fornecerá o núcleo essencial, embora não completo. Reclama e exige as disciplinas complementares. Em seu conjunto, porém, isto é, no currículo pleno, não deverá haver qualquer omissão prejudicial, nem, doutra parte, qualquer excesso. Nem demais, nem de menos $^{48}$ (grifos dos autores).

Compreendemos que houve uma tentativa de tratar o currículo com métodos e técnicas considerados eficientes à época. Entretanto, essa abordagem buscava uma

\footnotetext{
${ }^{47}$ Recomendação - Elaboração de Currículos, 1972.

${ }^{48}$ Recomendação - Elaboração de Currículos, 1972.
} 
metodologia neutra, sem preocupações com aspectos ligados à politização na educação. O currículo está permeado por relações de poder e saber, sendo assim, ele nunca será neutro ou desinteressado. Afinal, o currículo é um artefato de ação política, é uma ação que se fundamenta numa concepção de mundo, portanto é mais que um rol de disciplinas.

Dessa forma, com base nessas diretrizes elaboradas pelo Conselho de Graduação da UFMG, uma proposta de novo currículo ${ }^{49}$, para o curso da EEF-UFMG, foi levada à consideração da Congregação dessa instituição, em 08 de agosto de 1974, pelo então Diretor Pedro Ad. Víncula Veado Filho. Entre as propostas apresentadas estava a ampliação de três para quatro anos a duração do curso e o acréscimo de cargas horárias de várias disciplinas.

Com relação aos prazos e discussões que marcaram essa proposta, assim que acatada pela Congregação, ela foi enviada ao Colegiado de Curso, que elaborou um novo currículo, que foi aprovado em 24 de setembro de 1974, e, depois, encaminhado ao Conselho de Graduação da UFMG em 27 de setembro de 1974. Um curto o tempo, aproximadamente dois meses, entre a elaboração de uma proposta, as discussões, sua aprovação na EEF-UFMG e o encaminhamento aos órgãos superiores da UFMG.

Percebemos que essas mudanças, alteração do currículo e carga horária eram tratadas separadamente nos documentos. Como se modificações na carga horária não significassem transformações curriculares que impactariam os discursos oriundos dessas cadeiras. Além disso, prevalecia, nesses documentos, a ideia de currículo como rol de disciplinas, uma perspectiva que se aproxima das denominadas teorias curriculares tradicionais. Todavia, como se verá, essa proposta foi indeferida pelo Conselho de

\footnotetext{
${ }^{49}$ Proposta de novo currículo, 1974.
} 
Graduação da UFMG, o que impossibilitou a mudança curricular que se pretendia iniciar em 1975.

Conforme exposto, o Conselho de Graduação ${ }^{50}$ da UFMG aprovou um Parecer contrário à modificação do currículo da EEF-UFMG e elencou uma série de motivos para justificar a recusa, entre eles: alegou pressa da EEF-UFMG em elaborar um novo currículo; a não participação do corpo discente nesse processo; ementas incompletas ou iguais as anteriores e incoerência na conceituação de créditos.

Dessa forma, dada a não aprovação do currículo em 1974, o Conselho de Graduação da UFMG apresentou algumas propostas à EEF-UFMG para que, em outro momento, essa mudança curricular ocorresse. Em suma, deveria ser elaborada outra proposta, observando todas as críticas apontadas pelo referido Conselho. A Escola de Educação Física deveria, ainda, solicitar auxílio do Núcleo de Assessoramento Pedagógico (NAP) da UFMG para trabalhar essa questão ${ }^{51}$.

Tendo em vista a reprovação dessa primeira proposta de reforma curricular, o Colegiado do curso de EF designou uma comissão para estudar e elaborar uma nova proposta, atentando-se as recomendações do Conselho de Graduação ${ }^{52}$.

Foi o Decreto-Lei ${ }^{\circ}$ 69.450, de 1971, que determinou a integração da EF, como atividade escolar, no currículo de todos os graus de ensino (BRASIL, 1971). Com isso e conforme consta no relatório ${ }^{53}$ da nova proposta de mudança curricular, a formação de professores, à época, tinha o objetivo de capacitar os docentes a ministrar práticas de $E F$. Consequentemente, os currículos plenos, então vigentes, deveriam se ajustar a essa finalidade. Além de procurar atender a essa demanda legal, o corpo docente declarava

\footnotetext{
${ }^{50}$ Proposta de novo currículo, 1974.

${ }^{51}$ Proposta de novo currículo, 1974.

${ }^{52}$ Currículo Mudança 9, 1976.

${ }^{53}$ Currículo Mudança 2 - Escola de Educação Física da UFMG, 1976.
} 
que o currículo da EEF-UFMG padecia de um anacronismo, pois, com poucas adaptações, era o mesmo há vinte anos, desde os tempos da EEFMG.

E, assim, os docentes alegaram, na nova proposta $^{54}$, que ficaram dois anos (1974 a 1976) estudando, initerruptamente, as mudanças curriculares que desejavam e atentos aos problemas apontados pelo Conselho de Graduação da UFMG em 1974. Para isso, adotaram as seguintes medidas: entendimentos constantes com outras unidades/áreas interessadas, como a Faculdade de Educação e o Instituto de Ciências Biológicas; debates e estudos entre o corpo docente e discente da Escola de EF; busca de apoio do Núcleo de Assessoramento Pedagógico (NAP), cuidados com as orientações normativas da reforma e atenção às mudanças de nomes das disciplinas e discussões sobre as suas ementas. Em suma, todos os aspectos que foram alvos de críticas na primeira proposta de mudança curricular foram, atentamente, considerados nesse outro documento. Assim, em 1976, a EEF-UFMG encaminha uma nova proposta curricular $^{55}$ ao Conselho de Graduação da UFMG. Nesse documento, a modificação marcante referiu-se ao aumento de dois semestres letivos ao curso, passando de três para quatro anos no processo de formação em EF à época. Com relação à recreação, foram criadas as seguintes disciplinas: Teoria da Recreação; Prática da Recreação.

Estava enunciado que tal mudança de nomes das disciplinas se fazia necessária para que elas refletissem, tanto quanto possível, a essência de seu conteúdo. Além do mais, essa mudança nos nomes visava alterar a mera ordenação numérica da nomenclatura das cadeiras, nas quais era comum a abordagem de assuntos repetidos em outras disciplinas. Assim, Recreação I e Recreação II tornam-se, respectivamente,

\footnotetext{
${ }^{54}$ Currículo Mudança 2 - Escola de Educação Física da UFMG, 1976.

${ }^{55}$ Currículo Mudança 9, 1976.
} 
Teoria da Recreação e Prática da Recreação ${ }^{56}$.

Por fim, formalizando essa decisão, o Coordenador do Colegiado do Curso de Educação Física informa ao Diretor da EEF/UFMG, prof. Ellos Pires de Carvalho, em ofício $^{57}$ datado de 07 de dezembro de 1976, que o novo currículo da EEF-UFMG havia sido aprovado em 26 de novembro de 1976 pelos órgãos superiores da UFMG. Dessa forma, a proposta de reformulação do currículo da EEF-UFMG, enviada ao Conselho de Graduação da UFMG, foi aprovada e o curso de quatro anos passou a vigorar a partir de $1977^{58}$, sendo inseridas, na matriz curricular, as disciplinas Teoria da Recreação e Prática da Recreação.

\section{Disciplinas Teoria da Recreação e Prática da Recreação}

As disciplinas Teoria da Recreação e Prática da Recreação constaram na matriz curricular da EEF-UFMG no período de 1977 até 1990. Elas substituíram, respectivamente, as cadeiras de Recreação I e Recreação II. Essa mudança de nome era para atender às críticas que se faziam à época a simples ordenação numérica das cadeiras. Desse modo, ficaria claro o foco delas e, também, evitaria "a abordagem de assuntos repetidos numa e outra disciplina"

Antes da implantação das disciplinas Teoria da Recreação e Prática da Recreação era recorrente encontrar ementas, objetivos e conteúdos apresentados de forma idêntica nas disciplinas relativas a essa área. Com a alteração curricular, implantada em 1977, essas questões foram tratadas distintamente, uma vez que o nome das cadeiras prenunciavam a abordagem que se pretendia desenvolver à época.

\footnotetext{
${ }^{56}$ Currículo Mudança 2 - Escola de Educação Física da UFMG, 1976.

${ }^{57}$ Ofícios sobre mudança curricular, 1976 e 1981.

${ }^{58}$ Atas do Colegiado da EEF-UFMG, 1977.

${ }^{59}$ Currículo Mudança 2 - Escola de Educação Física da UFMG, 1976.
} 
Assim, a ementa relativa à Teoria da Recreação, na década de 1980, apontava que a disciplina:

Estuda e analisa o papel que as atividades recreativas desempenham no desenvolvimento e manutenção das condições físicas, intelectuais, sociais e emocionais do indivíduo, em diferentes idades. Enfatiza a importância da recreação na prática educativa e aponta seu valor para a vida quotidiana como preenchimento das horas de lazer ${ }^{60}$.

E a ementa da cadeira de Prática da Recreação evidenciava:

Tem por finalidade desenvolver atividades recreativas que contribuem para o satisfatório ajustamento e relacionamento social do indivíduo. Inclui o ensino de danças e canções folclóricas brasileiras e internacionais, brinquedos cantados, jograis e brincadeiras de salão. Ensina, sob forma de atividades recreativas exercícios de iniciação desportiva e explica como organizar e dirigir ruas de recreio ${ }^{61}$.

Dessa forma, enquanto o papel da primeira era estudar e analisar a recreação e o seu uso no preenchimento das horas de lazer, a segunda enfatizava o desenvolvimento, a organização e a direção de atividades recreativas diversas.

Para atingir esses fins, entre os enunciados pesquisados, constava que a disciplina Teoria da Recreação objetivava "explicar os fundamentos e princípios técnicos e pedagógicos da Recreação", além de "reconhecer a importância da Recreação como fator de ajustamento individual e social" ${ }^{\prime 62}$. Por sua vez, a disciplina Prática da Recreação apontava que os discentes deveriam "aplicar os conhecimentos adquiridos na disciplina Teoria da Recreação na prática do ensino da Educação Física” e para isso seria necessário "executar diversos tipos de danças, cantos, jogos, brincadeiras de salão e jograis comemorativos e folclóricos" ${ }^{\natural 3}$.

Mas, quais saberes estariam presentes nessas cadeiras? Houve mudanças nos discursos oriundos dos documentos analisados?

\footnotetext{
${ }^{60}$ Ementário, [198?].

${ }^{61}$ Ementário, [198?].

${ }^{62}$ Ementário, [198?].

${ }^{63}$ Ementário, [198?].
} 
$\mathrm{Na}$ busca de responder a essas questões, explicamos que essas disciplinas organizaram os conteúdos em unidades de ensino, assim como ocorreu com as suas predecessoras. Por exemplo, o programa de Teoria da Recreação ${ }^{64}$ apontava as seguintes unidades: 1 - Introdução à recreação; 2 - A recreação e a educação infantil; 3 Aplicação pedagógica da recreação; 4 - Recreação orientada; 5 - A educação do movimento através da recreação; 6 - Aspectos folclóricos da recreação.

De acordo com esse programa ${ }^{65}$, a unidade 1 tratava da origem desse vocábulo, sua história e classificação. A unidade 2 , da recreação no âmbito da educação física infantil, das atividades recreativas infantis que seriam desenvolvidas no programa escolar. A unidade 3 versava sobre os jogos e seu valor educativo, sua classificação, características, brinquedos cantados, danças folclóricas, ginástica historiada, fantoches e teatros. A unidade 4 era a que apresentava ampla diversidade de enunciações, pois focava na organização e desenvolvimento das Ruas de Recreio; na conceituação filosófica de interesse, prazer e dor; na recreação espontânea e orientada; dos parques infantis; nas atividades recreativas para o adolescente; no lazer para o adulto. Mencionava, também, as diversas possibilidades de atuação dos profissionais da recreação, como: os detentos, os habitantes da zona rural e os excepcionais. Por sua vez, a unidade 5 seria sucinta, abordava as expressões corporais ligadas à recreação e à matroginástica. Finalmente, a unidade 6 discutia o fato folclórico, as características do folclore e sua classificação, além de aspectos literários e lúdicos do folclore infantil utilizados na recreação.

Apesar de o vocábulo teoria estar presente na denominação dessa cadeira, as enunciações recém-explicitadas demonstram que as atividades de recreação, em sua

\footnotetext{
${ }^{64}$ Programa da Disciplina Recreação - Escola de Educação Física da UFMG, 1976-1980.

${ }^{65}$ Programa da Disciplina Recreação - Escola de Educação Física da UFMG, 1976-1980.
} 
dimensão prática, também seriam experiências propiciadas por essa disciplina. Todavia, percebemos que isso se caracterizou como uma exceção, pois as pistas oriundas das fontes demonstram que teoria e prática foram abordadas de forma dissociativa. Inclusive, a denominação das cadeiras ligadas à recreação seria representação dessa visão dissociativa.

Um ponto a destacar é que as enunciações apontavam a recreação como uma manifestação ligada à infância e à adolescência, enquanto o lazer seria uma vivência relacionada aos adultos. Esse discurso reforça a ideia da recreação como atividade, como jogos e brincadeiras infantis, tidas como algo não sério e voltado para as crianças.

De modo semelhante, o programa da cadeira Prática da Recreação ${ }^{66}$ também estava organizado em unidades de ensinos, classificados da seguinte maneira: 1 Danças como atividades recreativas; 2 - Brincadeiras de salão; 3 - Jogos como atividades recreativas; 4 - Brinquedos cantados; 5 - Jograis; 6 - Cantos; 7 - Ruas de Recreio; 8 - Recreação aplicada às atividades de iniciação desportiva. No interior dessas unidades de ensino, eram apontados os tipos de jogos, brincadeiras, danças, jograis que seriam desenvolvidos. Por exemplo, na primeira unidade ${ }^{67}$, seriam trabalhadas as danças nacionais, as danças regionais e as danças internacionais e na segunda, as brincadeiras que poderiam ocorrer em diversos espaços como clubes, salões e sala de aula.

Dessa forma, as enunciações presentes nas fontes evidenciam a visão predominantemente técnica e metodológica que demarcou a cadeira Prática da Recreação. Apesar da prevalência dessas ações práticas, houve uma pequena mudança na forma como os discursos se manifestaram nos documentos, ou seja, antes era apresentado um rol de atividades, uma relação de jogos, brinquedos, brincadeiras e

\footnotetext{
${ }^{66}$ Programa da Disciplina Recreação - Escola de Educação Física da UFMG, 1976-1980.

${ }^{67}$ Programa da Disciplina Recreação - Escola de Educação Física da UFMG, 1976-1980.
} 
danças que ocorreriam sem especificar uma relação entre elas. Exemplificando melhor essa questão, a disciplina Recreação, ofertada na EEFMG ${ }^{68}$, recomendava o desenvolvimento das seguintes atividades: dança do ganso, dança do caçador, moça, fazenda, sinhá marreca, quem é o maestro, estrada em curva, sinhá marreca entre outras possibilidades de jogos e cantigas.

Com as mudanças curriculares ocorridas na EEF-UFMG, essas atividades práticas passaram a compor outra unidade de ensino, ou seja, a compor a unidade denominada Brinquedos $\operatorname{Cantados}^{69}$, por exemplo. Contudo, compreendemos que tal mudança se deu na forma, mas não na essência.

Por fim, ao apresentar essa dimensão técnico-metodológica, não almejamos negar essa visão na formação em $\mathrm{EF}$, pois compreendemos que essa questão contribui/contribuiu para as ações desenvolvidas pelos profissionais na área. O que questionamos é o excesso dessa racionalidade técnica ${ }^{70}$, o que colabora para desumanizar a razão, quando desprovida de uma concepção de ensino que abarque uma formação humanista (GIROUX, 1986).

\section{Mudanças de Protagonismo}

Contudo, na década de 1980 ocorreram mudanças de protagonismo nas disciplinas Teoria da Recreação e Prática da Recreação na EEF-UFMG. Inicialmente, em virtude da aposentadoria da professora Nella Testa Taranto em $1983^{71}$, sendo substituída pela professora Leila Mirtes Santos de Magalhães Pinto. Depois, em 1988,

\footnotetext{
${ }^{68}$ Matéria Lecionada Recreação, 1963.

${ }^{69}$ Programa da Disciplina Recreação - Escola de Educação Física da UFMG, 1976-1980.

${ }^{70}$ Essa racionalidade técnica acaba por reduzir tudo a uma questão de custo-benefício, em um modelo que privilegia saberes pragmáticos, utilitaristas, em detrimento de saberes mais questionadores da vida política, econômica e cultural dos sujeitos (LYON, 1998).

${ }^{71}$ No CEMEF há um documento com os dados biográficos da professora Nella, no qual está relatado que ela se aposentou, provavelmente, em agosto de 1983.
} 
sobreveio o falecimento do professor Odilon Ferraz Barbosa e, então, a professora Ydalga Maria Ribas Rezende assumiu, junto com a professora Leila, essas cadeiras. Além desses fatos, nos programas de ensino, a partir de 1989, também apareceu o nome da professora Marilita Aparecida Arantes Rodrigues como docente na cadeira de Prática de Recreação ${ }^{72}$. Consta, ainda, na ata do Departamento ${ }^{73}$ de EF da EEF-UFMG, de 28/12/1988, que o professor Túlio Max Ferreira Leite ${ }^{74}$ também atuara nessa cadeira. As participações dos docentes Túlio e Marilita, nessas disciplinas, ocorreram assim que a professora Leila se afastara para cursar o Mestrado em Educação Física, na linha de pesquisa sobre o Lazer, na Universidade Estadual de Campinas (UNICAMP) ${ }^{75}$.

Dessa forma, com base nesses dados, elaboramos o Quadro 1 com o intuito de visualizar a relação disciplinas, instituição, período e professores dessas cadeiras.

\section{Quadro 1: Docentes das disciplinas de Recreação: 1963-1990}

\begin{tabular}{l|l|l|l}
\hline \multicolumn{1}{c|}{ Disciplina } & \multicolumn{1}{c|}{ Instituição } & \multicolumn{1}{c}{ Período } & \multicolumn{1}{c}{ Docentes Responsáveis } \\
\hline Recreação & EEFMG & 1963 a 1969 & $\begin{array}{l}\text { Geraldo Gomes de Souza } \\
\text { Odilon Ferraz Barbosa }\end{array}$ \\
\hline Recreação & EEF-UFMG & 1970 a 1972 & $\begin{array}{l}\text { Odilon Ferraz Barbosa } \\
\text { Nella Testa Taranto }\end{array}$ \\
\hline $\begin{array}{l}\text { Recreação I } \\
\text { Recreação II }\end{array}$ & EEF-UFMG & 1973 a 1976 & $\begin{array}{l}\text { Odilon Ferraz Barbosa } \\
\text { Nella Testa Taranto }\end{array}$ \\
\hline $\begin{array}{l}\text { Teoria da Recreação } \\
\text { Prática da Recreação }\end{array}$ & EEF-UFMG & 1977 a 1990 & $\begin{array}{l}\text { Odilon Ferraz Barbosa } \\
\text { Nella Testa Taranto } \\
\text { Leila Mirtes S. M. Pinto } \\
\text { Ydalga M. Ribas Rezende } \\
\text { Marilita Ap. A. Rodrigues } \\
\text { Túlio Max Ferreira Leite }\end{array}$ \\
\hline
\end{tabular}

Fonte: Arquivos do Departamento de EF da EEFFTO-UFMG e Acervo do CEMEF-UFMG.

Com relação à mudança de protagonismo na disciplina Teoria da Recreação, dada a aposentadoria da professora Nella Testa Taranto e a inserção da professora Leila Mirtes como docente nessa cadeira, inicialmente não encontramos mudanças nas

\footnotetext{
72 Programas Prática Recreação, 1987 a 1989.

${ }^{73}$ Atas da Câmara do Departamento de Educação Física da UFMG, 1986 a 1991.

${ }^{74}$ Não encontrei enunciações da atuação do professor Túlio nas cadeiras de Teoria da Recreação ou Prática da Recreação. Isso gerou dúvidas se a atuação do professor Túlio, nessa área, ocorrera antes ou depois de 1990.

${ }^{75}$ Atas da Câmara do Departamento de Educação Física da UFMG, 1986 a 1991.
} 
enunciações, mas paulatinamente alterações foram surgindo nos programas de ensino da época. Outras deixaram de fazer parte dos documentos, como as enunciações ligadas aos aspectos folclóricos, ao fato folclórico e a carta folclórica ${ }^{76}$.

Quanto aos objetivos dessa cadeira, por exemplo, houve mudanças no programa de ensino de 1988, quais sejam:

- Refletir sobre conceitos e significados de Recreação, de Lazer, do lúdico e do jogo na sociedade contemporânea;

- Conhecer e analisar a evolução histórica da Recreação e dos estudos sobre o Lazer;

- Discutir acerca da relação das questões fundamentais da Recreação e Lazer e as questões da área da Educação Física Brasileira;

- Analisar ações desenvolvidas na Recreação e Lazer buscando compreender a predominância dos interesses, as características, gêneros e níveis;

- Conhecer e analisar o contexto sócio-econômico-políticoeducacional onde são desenvolvidas ações da Recreação e Lazer no cotidiano de nossa população e junto a instituições, públicas e particulares;

- Levantar temáticas para aprofundamentos de estudos e ação profissional em relação à área Recreação e Lazer ${ }^{77}$.

E, para atingir esses objetivos, as unidades de ensino abordariam as seguintes questões: 1 - Introdução à Recreação e estudos sobre o Lazer; 2 - Atividades da Recreação e Lazer; 3 - A Recreação e Lazer na Sociedade Brasileira. Consta nos documentos que entre as abordagens metodológicas utilizadas estavam os debates, as palestras, os seminários, a mesa redonda e análise de filmes ${ }^{78}$.

Essas enunciações, presentes nos objetivos, nas unidades de ensino e nas abordagens metodológicas, demonstram que as questões ligadas ao lazer passaram a ter proeminência nas discussões dessa cadeira. Isso não significou que a temática da recreação deixara de ser abordada, mas sim que estaria acompanhada das reflexões sobre o lazer. A recreação e lazer passaram a constar, conjuntamente, nas fontes ligadas

\footnotetext{
${ }^{76}$ Programas Teoria Recreação, 1987 a 1990.

${ }^{77}$ Programas Teoria Recreação, 1987 a 1990.

${ }^{78}$ Programas Teoria Recreação, 1987 a 1990.
} 
à cadeira Teoria da Recreação. Inclusive, a unidade de ensino 1 - Introdução à Recreação e estudos sobre o Lazer, teve a mesma denominação da disciplina que foi implantada na matriz curricular da EEF-UFMG a partir de 1991.

Essas transformações nas enunciações, conectando recreação e lazer, também passaram a operar na cadeira Prática de Recreação. Exemplificando, nos programas de ensino dessa disciplina, de 1988, as enunciações relacionadas aos objetivos explicitavam que ela visava propiciar ao aluno "refletir sobre os princípios e fundamentos do brinquedo infantil, do jogo e do comportamento no lazer" e, também, “conhecer e discutir a política nacional e estadual para a área de Recreação/Lazer"79. Exemplos disso manifestavam-se até mesmo nas ações desenvolvidas, ou seja, entre os projetos de ensino propostos nessa cadeira, havia: Atividades recreativas na FEBEM (Fundação Estadual para o Bem Estar do Menor) e também Lazer na comunidade ${ }^{80}$.

Consequentemente, os conteúdos desenvolvidos passaram a apresentar outros elementos além dos jogos, brinquedos, brincadeiras e cantigas ligadas à recreação. A temática do lazer também foi abordada nessa cadeira, essencialmente voltada às questões práticas, ou seja, aos aspectos ligados ao comportamento no lazer, às Ruas de Lazer e, também, às políticas para a recreação e o lazer ${ }^{81}$.

Pesquisando, ainda, os programas de ensino de 1988, detectamos pistas sobre os protagonismos de alguns docentes, manifestos nas mudanças e permanências nos discursos dessa cadeira. Referimo-nos ao papel de cada docente no sistema de avaliação adotado à época, no qual estavam enunciados os critérios/pontuação a serem avaliados pelos professores. Assim, cabia ao professor Odilon avaliar o conteúdo prático, através de provas escritas, enquanto pertencia à professora Leila a incumbência de aferir o

\footnotetext{
${ }^{79}$ Programas Prática Recreação, 1987 a 1989.

${ }^{80}$ Programas Prática Recreação, 1987 a 1989.

${ }^{81}$ Programas Prática Recreação, 1987 a 1989.
} 
conteúdo teórico, as questões ligadas ao comportamento no lazer e a política para o $\operatorname{lazer}^{82}$.

Ainda sobre os planos de ensino da disciplina Prática de Recreação, com o falecimento do professor Odilon, a professora Ydalga assumiu essa cadeira com a professora Leila, e as questões sobre o lazer ganharam um protagonismo maior nesses documentos. Nesse sentido, citamos o programa de ensino de 1989, no qual, das sete unidades de ensino, quatro eram voltadas ao lazer, a saber: A educação pelo e para o Lazer; Atividades de Lazer dentro e fora da Escola; A liderança no Lazer; Política para a Recreação/Lazer ${ }^{83}$. Cabe ressaltar que, mesmo com a licença da professora Leila para cursar o mestrado, essa discussão sobre o lazer se manteve com a entrada da professora Marilita Aparecida Arantes Rodrigues na docência dessa cadeira ${ }^{84}$.

Conforme demonstramos ao longo deste texto, as fontes evidenciaram que foram mudanças de protagonismo que marcaram as mudanças de discursos sobre essas áreas. Ressaltamos, porém que não se tratou da mudança de protagonismo individual, mas sim de uma mudança que tinha o mote do coletivo. Portanto, o trabalho em grupo se caracterizou como um elemento essencial para a mudança nos discursos. $\mathrm{O}$ protagonismo não era mais particular, mas em conjunto. Esse protagonismo coletivo foi propício à criação de um ambiente que incentivava a troca de saberes, afinal, percebemos que é difícil estabelecer um campo, uma área de atuação, apenas com ações individuais.

Nessa medida, enquanto um grupo liderado pela professora Leila se aproximava do campo do lazer, outro associado ao professor Odilon se consolidava na área da recreação. Inclusive, a denominação utilizada por docentes diferentes em suas ações de

\footnotetext{
82 Programas Prática Recreação, 1987 a 1989.

${ }^{83}$ Programas Prática Recreação, 1987 a 1989.

${ }^{84}$ Programas Prática Recreação, 1987 a 1989.
} 
extensão, como, Ruas de Recreio ou Manhãs de Lazer, evidencia as diferentes visões sobre essas temáticas à época. Isso demonstra, também, que esses professores tinham, pelo menos, as aulas como um espaço de autonomia.

\section{Considerações Finais}

Ao investigar os discursos emanados dos currículos oficiais da EEF-UFMG, tivemos que compreender as relações de poder e saber manifestas nos documentos consultados. Relações essas muito estreitas e íntimas, nas quais discutimos que o poder precisa de discursos que corroborem certos saberes para que seja legitimado. Da mesma forma, todo saber necessita das relações de poder para que seja considerado verdadeiro. Assim, poder e saber estão imbricados por uma recíproca dependência.

Outra questão que procuramos demonstrar diz respeito aos conceitos presentes nesse campo que não se sistematizaram de forma linear ou harmoniosa, formando uma linha única. Pelo contrário, algumas vezes, esses saberes se opunham entre si e apresentavam possibilidades de caminhos diversos a serem seguidos. Por conseguinte, buscamos observar o conjunto de enunciados que se agrupava como um discurso, percebendo então, não só conceitos iguais em períodos distintos, como também mudanças significativas em uma mesma época.

As disciplinas Teoria da Recreação e Prática da Recreação foram ofertadas no período de 1977 a 1990, com carga horária semestral de 60 horas/aula cada uma. Elas substituíram, respectivamente, Recreação I e Recreação II e a partir de 1991, com outra mudança curricular ocorrida na EEF-UFMG, foram extintas, retiradas, da matriz curricular.

Com referência aos discursos relativos à recreação, foram demarcados por 
enunciações que os relacionavam a diversos aspectos, entre eles: às sessões de pequenos e grandes jogos; à associação entre os jogos e a recreação, mas numa perspectiva técnico-metodológica; ao jogo em caráter recreativo, o jogo recreativo; à recreação ativa e passiva; à recreação como arma de dois gumes, ou como instrumento de dois gumes; às Ruas de Recreio. Ressaltamos, ainda, que a recreação ligava-se às enunciações interesse e prazer, logo, a busca pela diversão caracterizava essa área. Assim, nesse contexto, recreação associava-se a jogos, recreação e infância. Daí a manifestação de uma abordagem técnica e metodológica de reprodução de atividades, com fins de canalizar as tensões e amenizar os problemas sociais. Contudo, ao mesmo tempo, a recreação se entrecruzava com os discursos biológico, psicológico e sociológico numa tentativa de superar a perspectiva biológica presente na formação da época.

Compreendemos que foram as mudanças de protagonismo que fomentaram mudanças nos discursos sobre um determinado saber. Afinal, as discussões mostraram que a federalização, as mudanças nas matrizes curriculares, os aspectos legais, o regime ditatorial, a criação e a extinção de disciplinas pouco impactaram os discursos proferidos sobre a recreação e o lazer na EEFFTO-UFMG.

Por fim, ao analisar as fontes desta pesquisa, percebemos que elas não podem ser consideradas um espelho exato da realidade, mas uma representação de momentos particulares dela. Assim, é necessário compreender que os estudos relativos à recreação são marcados historicamente, ou seja, os significados atribuídos a essas temáticas em determinado período não podem ser transferidos, mecanicamente, a outras épocas e contextos. 


\section{REFERÊNCIAS}

BRASIL. DECRETO-LEI No 997, de 21 de outubro de 1969. Integra estabelecimentos de ensino superior em Universidades das áreas geo-educacionais em que estão situados. Brasília, 1969. Disponível em: http://www2.camara.leg.br/legin/fed/declei/19601969/decreto-lei-997-21-outubro-1969-375211-publicacaooriginal-1-pe.html . Acesso em: 13 nov. 2016.

LEI No 5.692, de 11 de agosto de 1971. Fixa as Diretrizes e Bases para o ensino de $1^{\circ}$ e $2^{\circ}$ graus, e dá outras providências. Brasília, 1971. Disponível em: < http://www2.camara.leg.br/legin/fed/lei/1970-1979/lei-5692-11-agosto-1971-357752publicacaooriginal-1-pl.html> . Acesso em: 01 mar. 2017.

CARTA do Folclore Brasileiro. In: Anais do I CONGRESSO BRASILEIRO DE FOLCLORE. Rio de Janeiro, ago de 1951. Disponível em: https://www.google.com.br/url?sa $=\mathrm{t} \& \mathrm{rct}=\mathrm{j} \& \mathrm{q}=\&$ esrc $=\mathrm{s} \&$ source $=$ web $\& \mathrm{~cd}=3 \& \mathrm{cad}=\mathrm{rja} \&$ uact $=8 \&$ ved=0ahUKEwil97vo_vfSAhUBHJAKHW0CB00QFggmMAI\&url=http $\% 3 \mathrm{~A}$ $\% 2 \mathrm{~F} \% 2 \mathrm{Fhugoribeiro.com} . \mathrm{br} \% 2 \mathrm{Fbiblioteca}-$

digital\%2FCarta_do_folclore.odt\&usg=AFQjCNFsBJF2wBOO9pQAtwC7ATi7x

WcImw\&bvm=bv.150729734,d.Y2I . Acesso em 27 mar. 2017.

CNFCP, Centro Nacional de Folclore e Cultura Popular. Edison Carneiro (1912 1972). Rio de Janeiro, 2017. Disponível em: http://www.cnfcp.gov.br/interna.php? ID_Materia=162. Acesso em 27 mar. 2017.

FEIX, Eneida. Lazer e cidade na Porto Alegre do início do século XX: a institucionalização da recreação pública. 2003. Dissertação (Mestrado em Ciências do Movimento Humano) - Programa de Pós-Graduação em Ciências do Movimento Humano, Escola de Educação Física. Universidade Federal do Rio Grande do Sul, 2003.

FOUCAUlT, Michel. A Arqueologia do Saber. 7. ed. Rio de Janeiro: Forense Universitária, 2008.

GAELZER, Lenea. Recreação. In: Apostila da Associação Brasileira de Recreação ABDR. III Curso de Informações, por correspondência, sobre Recreação. Rio de Janeiro: ABDR, 1973. Mimeografado.

GIROUX, Henry. Racionalidade e a crítica da razão instrumental. In: Teoria Crítica e Resistência em Educação. Petrópolis: Vozes, 1986. p.26-33.

GOMES, Christianne Luce. Significados de recreação e lazer no Brasil: reflexões a partir de análises de experiências institucionais $(1926$ - 1964). 2003. 322f. Tese (Doutorado em Educação) - Programa de Pós-Graduação em Educação, Universidade Federal de Minas Gerais, Belo Horizonte, 2003.

GOODSON, Ivor. La construcción social del curriculum: possibilidades y ambitos de investigación de la historia del curriculum. Revista de Educación. Madri, 295, pp. 737, mayo-agosto, 1991. 
GOUVÊA, Ruth. A presença do recreador. In: Apostila da Associação Brasileira de Recreação - ABDR. III Curso de Informações, por correspondência, sobre Recreação. Rio de Janeiro: ABDR, 1973. Mimeografado.

. CAMPOS, M. E. R.; CUNHA, M. A. Jogos infantis. São Paulo: Nacional; Departamento de Educação do Distrito Federal, 1934.

Os jogos dirigidos na educação integral. Revista de Ensino, Belo Horizonte, v.17, n.193, p.177-84, jul.-dez 1949.

Recreação. Rio de Janeiro: Agir, 1963.

LIMA, João Franco. Ethel Bauzer Medeiros: trajetória no campo da recreação e do lazer. 2009. Dissertação (Mestrado Interdisciplinar em Estudos do Lazer) - Programa de Pós-Graduação Interdisciplinar em Estudos do Lazer, Universidade Federal de Minas Gerais, Belo Horizonte, 2009.

LYON, David. Pós-Modernidade. São Paulo: Paulus, 1998.

MAGAlHÃES, Justino. Cultura Escrita e Modernização Educativa. Disciplina ofertada no programa de Pós-Graduação em Educação da Faculdade de Educação da UFMG. Belo Horizonte, 2013. Notas de aula.

MEDEIROS, Ethel Bauzer. Atividade Criadora - conceituação. In: Apostila da Associação Brasileira de Recreação - ABDR. III Curso de Informações, por correspondência, sobre Recreação. Rio de Janeiro: ABDR, 1973. Mimeografado.

OLIVEIRA, Guilherme de Souza Lima. Concursos públicos para provimento de cadeira de Educação Física em Escolas Estaduais Mineiras (1960-1974): o lugar da Escola de Educação Física de Minas Gerais. 2014. 118f. Dissertação (Mestrado em Educação) - Programa de Pós-Graduação em Educação: Conhecimento e Inclusão Social, Universidade Federal de Minas Gerais, Belo Horizonte, 2014.

ROSA, Maria Cristina; LINHALES, Meily Assbú (Org.). Guia de Fontes: Acervo do Centro de Memória da Educação Física, do Esporte e do Lazer. Belo Horizonte, 2007. $203 \mathrm{p}$.

SILVA, Marina Guedes Costa. Uma História da Recreação (1952-1970): constituição inicial da disciplina na Escola de Educação Física de Minas Gerais. 2005. 35f. Monografia (Graduação em Educação Física) - Universidade Federal de Minas Gerais, Belo Horizonte, 2005.

TEIXEIRA, Sérgio. O lazer e a recreação na Revista Brasileira de Educação Física e Desportos como dispositivos educacionais (1968-1984). 2008. 251f. Dissertação (Dissertação em Educação). Programa de Pós-Graduação em Educação da Universidade Federal de Uberlândia. Uberlândia, MG, 2008. 
VEIGA-NETO, Alfredo José. A ordem das disciplinas. 1996. 344f. Tese (Doutorado em Educação) - Programa de Pós-Graduação em Educação, Universidade Federal do Rio Grande do Sul (UFRGS), Porto Alegre, 1996.

VIÑAO, Antônio. A história das disciplinas escolares. Revista Brasileira de História da Educação, n. 18, set./dez., 2007, p. 172-215.

\section{FONTES}

- Acervo do Centro de Memória da Educação Física, do Esporte e do Lazer (CEMEF) da EEFFTO-UFMG.

- $\quad$ Arquivos da seção de ensino da EEFFTO-UFMG.

- $\quad$ Arquivos do Colegiado de Graduação em Educação Física da EEFFTO-UFMG.

- $\quad$ Arquivos do Departamento de Educação Física da EEFFTO-UFMG.

- $\quad$ Atas da Congregação da EEFFTO-UFMG.

\section{Endereço dos Autores:}

Hilton Fabiano Boaventura Serejo

Rua das Sucupiras, 51, Bairro Vila Arraiolo,

Diamantina - MG - 39.100-000

Endereço Eletrônico: hiltonserejo@uol.com.br

Hélder Ferreira Isayama

EEFFTO/UFMG

Av. Antônio Carlos 6627, Pampulha

Belo Horizonte - MG - 31.270-901

Endereço Eletrônico: helderisayama@yahoo.com.br 